\title{
EVALUATION OF PHEROMONE TRAPPING FOR PREDICTION OF DIAMONDBACK MOTH INFESTATIONS IN VEGETABLE BRASSICAS
}

\author{
G.P. WALKER ${ }^{1}$, A.R. WALLACE ${ }^{2}$, R. BUSH ${ }^{3}$, F.H. MACDONALD ${ }^{1}$ \\ and D.M. SUCKLING ${ }^{4}$
}

\author{
${ }^{1}$ Crop \& Food Research, PB 92169, Auckland \\ ${ }^{2}$ Crop \& Food Research, PB 4704, Christchurch \\ ${ }^{3}$ Pukekohe Growers Supplies Limited, 45 Kitchener Rd, Pukekohe \\ ${ }^{4}$ HortResearch, P.O. Box 51, Lincoln \\ Corresponding author: walkerg@crop.cri.nz.
}

\begin{abstract}
The use of pheromone traps was investigated as a monitoring tool to forewarn crop scouts of risk periods when diamondback moth (DBM; Plutella xylostella) larval numbers in crops are likely to increase to damaging levels. We monitored traps at five brassica planting sites for 8 months and also counted numbers of DBM larvae on 50-100 plants at each site. Crops were scouted weekly and insecticide application decisions were made using the Crop \& Food Research IPM programme. Results showed that increases in moth trap catches predicted increases in larval infestations in three of four commercial crops in spring by 2-3 weeks and gave 2 weeks warning in four of five summer crops. An epizootic of Zoophthora radicans caused a rapid decline in larval populations in mid to late January at all sites. In these trials, use of the IPM action thresholds led to a $75 \%$ reduction in insecticide use on vegetable brassica crops. Overall, pheromone traps were of limited value, except in early spring, because crops needed to be scouted regularly for other pests.

Keywords: diamondback moth, Plutella xylostella, pheromone traps, IPM, Zoophthora radicans.
\end{abstract}

\section{INTRODUCTION}

Diamondback moth (DBM; Plutella xylostella) is found throughout the world and is considered the most destructive insect pest of crucifer brassica crops (Talekar \& Shelton 1993). The traditional method of control for this pest relies upon regular applications of insecticides from planting to harvest. This has led to major problems with insecticide resistance in DBM in New Zealand (Walker et al. 2001). Recently, Crop \& Food Research has developed and implemented an integrated pest management (IPM) programme for vegetable brassicas (Berry 2000) that is based on crop scouting and uses validated action thresholds to aid insecticide resistance management in DBM.

Pheromone traps can assist decision support systems in IPM programmes, and recent studies have demonstrated a considerable improvement in the blends of pheromones available for use in traps for DBM in New Zealand (Suckling et al. 2002). We investigated the use of pheromone traps, using the most attractive pheromone blend, as a potential tool to forewarn growers or crop managers of risk periods when DBM larval numbers in their crops are likely to increase to economically damaging levels. Previous work overseas by Baker et al. (1982) showed that adult DBM catches correlated with subsequent larval populations, which occurred 11-21 days later. Use of these traps might reduce the time required to scout the crops, and pheromone trap catches could also aid in decisions on initiation and required frequency of crop scouting in spring. 


\section{MATERIALS AND METHODS \\ Pheromone trap placement and maintenance}

Pheromone traps were positioned in one newly planted crop at each of five brassicagrowing sites in South Auckland on 12 September 2000. Four sites were commercial production areas at Bombay, Puni, Tuakau and Drury, with plantings varying in size from 1-3 ha. The fifth site was an experimental area at the Pukekohe Research Centre (PRC), Pukekohe. Varieties planted were cabbage at PRC and Puni, broccoli at Bombay and Drury, and a mix of cabbage and cauliflower at Tuakau. At the commercial sites, five traps were placed in the new planting, one trap being positioned in the centre of the crop and four traps were positioned $10 \mathrm{~m}$ in from the edge of the mid-point of each side of the planting. The traps were labelled as north, east, south, west and centre traps. Traps were positioned about $30 \mathrm{~cm}$ above the ground when plants were small and adjusted upwards as required to remain just above the crop canopy. At the non-commercial site at PRC, the plantings were small, about 600 plants, in four rows of $60 \mathrm{~m}$ length, and only two traps were deployed at this site, $10 \mathrm{~m}$ in from the east and west ends of each rectangular planting.

Pheromone lures consisted of a rubber septum impregnated with a standard amount of the best pheromone blend as determined in previous studies (Suckling et al. 2002). These were placed in the centres of the sticky bases in standard delta traps (Suckling \& Shaw 1990). Lures were replaced every 3 weeks, and the sticky bases in traps were replaced when traps were moved, or as required, when the sticky surfaces were clogged with moths or if the surfaces had lost adhesiveness.

\section{Trap monitoring and crop management}

All traps and corresponding plantings were monitored weekly until harvest stage for each crop when traps were moved to an adjacent, new planting. Sites were monitored weekly throughout three crop cycles at four sites and for two crop cycles at the fifth site at Drury. Moths were not removed from the sticky trap bases. The total numbers of moths present were recorded each week and the mean number of moths caught per trap per week was calculated for each site from these cumulative counts.

At all commercial sites, the numbers of DBM larvae per plant were counted from 50 or 100 randomly selected plants. Fifty plants were sampled at each site until larval infestations increased to more than $2-3$ per 50 plants, at which stage the number of plants sampled was increased to 100 , following the vegetable brassica scouting technique developed by Beck et al. (1992). When sufficient numbers of DBM larvae were available, collections of 30+ larvae were made and reared individually to assess the incidence and impact of natural enemies on DBM larval populations. These studies on natural enemies are described in Walker et al. (2002). At PRC, only 50 plants were sampled throughout the season because of the small area involved.

Overall pest infestations were assessed using the Crop \& Food Research IPM programme (Berry 2000). The scouting technique uses "percent of plants infested" action thresholds, which avoids the need to count all pests present and is easy for growers or commercial scouts to use. The cabbage threshold for lepidopteran larvae is $15 \%$ infested plants, while the broccoli and cauliflower thresholds for larvae depend on plant development stage, being $30 \%$ at seedling stage, $20 \%$ at leafy stage to floret or curd formation, then $10 \%$ for florets and 5\% for curds (Berry 2000). The action threshold for aphids for all varieties is $10 \%$ infested with colonies. Insecticides were applied if the action thresholds were exceeded for the particular plant varieties, following the DBM insecticide resistance management rotation strategy (Walker 2001). This rotation strategy recommends the use of selective insecticides to maximise the impact of natural enemies on DBM larval populations and other pest species.

\section{Pheromone trap placement}

\section{RESULTS AND DISCUSSION}

Over the whole season, differences in moth trap catches were not related to any geographical direction of the traps in the crops. However, moth catches appeared to be higher in the trap (or traps) nearer older plantings. At the Drury site, the mean weekly catch 
for the centre trap was only about half the mean for the four outer traps $(\mathrm{P}<0.05)$; being 2.0 for the centre trap and 4.3 for the outer traps for the first crop, and 24.2 and 41.8 respectively for the second crop. This may have been because the site was planted for the first time in brassicas, and was isolated from other brassica crops. Infestations may have originated from small numbers of moths infesting the edge of the crop, with the progeny slowly spreading into the middle, with little other outside recruitment.

\section{Trap monitoring and crop management}

Results from moth trap catches and crop scouting for DBM larval infestations are presented in Figure 1. At all sites, crop scouting began 1 week after placing the traps in the crops and continued each week until all the traps were removed. Scouting ceased in early May, when crops were considered to be safe from DBM larval infestations. Crop scouting started early enough in the season to detect early insect pest infestations, which consisted of small populations of green peach aphid, Myzus persicae, infesting two of the four commercial crops. Other insect pest infestations increased rapidly in mid October when DBM and white butterfly (Pieris rapae) larvae infested 10-14\% of all plants at all commercial sites.

From the time of trap placement, moths were caught every week in nearly every trap at every site. Initially the numbers caught were low, with means over the first five weeks being less than seven per trap per week at all sites (Fig. 1). An increase in moth numbers to about eight or more per trap occurred 0-3 weeks before the first larval infestations (defined as at least one larva per 7 plants). At the beginning of October at two sites (Bombay and Drury) small increases in moth trap catches of 3-5 times and 2-4 times over a two week period, preceded DBM larval infestations of $14 \%$ and $10 \%$ of plants infested respectively later in the month. These crops were both broccoli, where the action threshold is higher than in cabbage at the leafy stage (Berry 2000). In this case, these larval infestations did not require control.

In all four spring/early summer commercial crops (crop 1 for each site, Fig. 1), there were small outbreaks of DBM larvae. These required spray applications at two sites. Increases in moth trap catches (by about 2-3 times the number of moths) preceded the build-up of DBM larvae in these crops at three of the four commercial sites. In the other crop, at Tuakau, increased moth trap catches did not precede the small but damaging larval infestation in this crop (which required spraying), but occurred on the same day that damaging populations of larvae were detected. At PRC there were very few DBM, either moths or larvae, until early December, when an increase in moth numbers was followed 2 weeks later by a large larval infestation (Fig. 1). Many DBM parasitoids were recorded at PRC (Walker et al. 2002) and many generalist predators were observed in spring at this site. Their activity probably reduced DBM populations.

In the summer crops (the second planting), moth trap catches gave two weeks warning (a 2-10 times increase in number of moths) of damaging larval infestations (increases from $0-5 \%$ to $21-92 \%$ of plants infested) in all crops except at Tuakau. An early spray was required at Tuakau when the seedlings were found to be $17 \%$ infested one week after transplanting. This infestation probably originated from a neighbouring heavily infested older crop.

During the early growth period for the third crop, from late February to mid March, weekly moth trap catches were high and were not useful for predicting larval infestations, which occasionally required insecticide applications (Fig. 1). In autumn, infestations of large looper (Thysanoplusia orichalcea) and large white butterfly larvae required control.

In mid to late January an epizootic of Zoophthora radicans occurred that was associated with warm, moist conditions. This led to a collapse in DBM larval numbers, particularly at the PRC and Bombay sites. This fungal pathogen is naturally occurring and can decimate DBM populations in mid and late summer if conducive weather conditions are associated with large larval populations. The epizootic was evident at all sites but much more noticeable at PRC where larval infestations were much higher than at other sites (up to seven DBM larvae per plant). DBM larval populations declined dramatically at all sites during this period (Fig. 1) and parasitism by the important larval parasitoid Diadegma semiclausum was adversely affected by $Z$. radicans at the unsprayed site (Walker et al. 2002). 


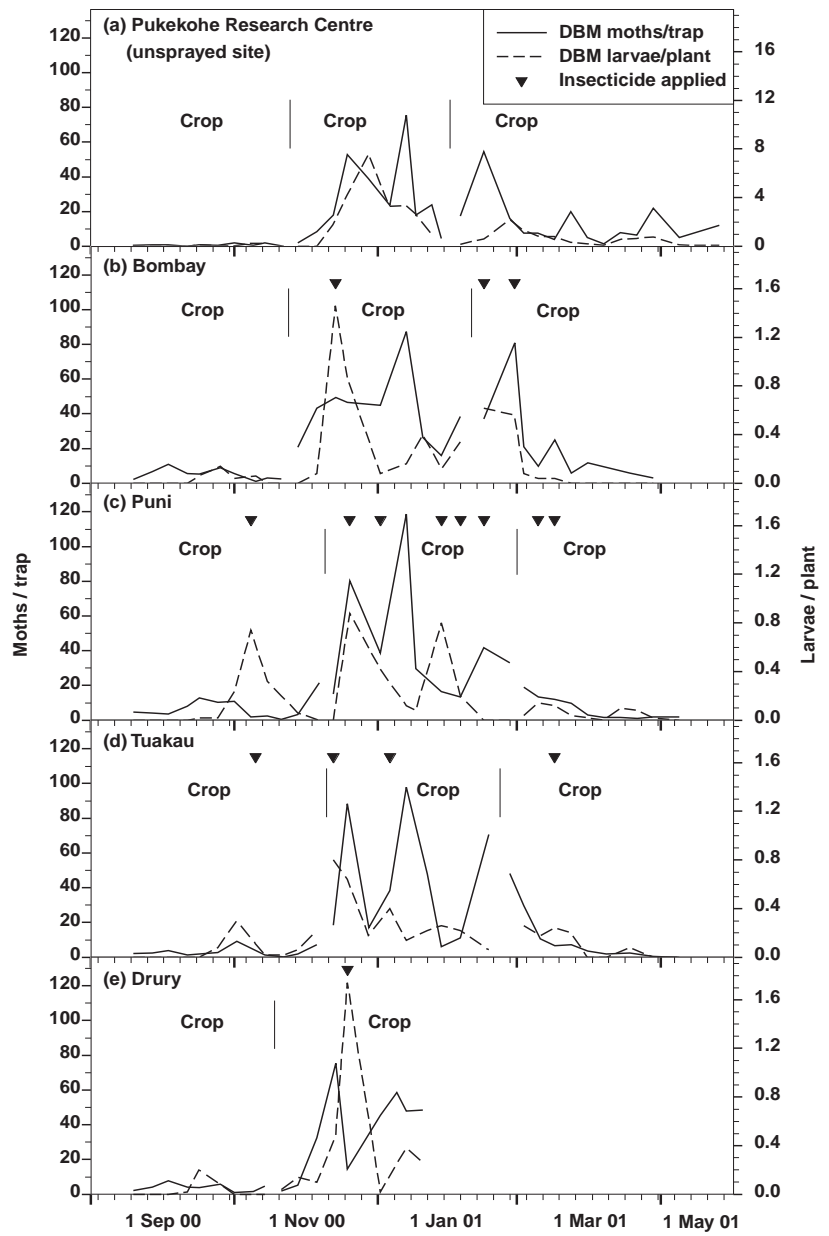

FIGURE 1: Mean numbers of diamondback moth (DBM) adults caught per pheromone trap per week and average number of larvae per plant from 50 or 100 plants sampled weekly. Data are for five brassicagrowing sites in south Auckland in the 2000/01 season. The timing of insecticide applications is indicated. Breaks in the data lines indicate removal of traps from crops about to be harvested and transfer to newly planted adjacent crops.

This study highlights the benefits of the IPM programme to minimise insecticide use. In the four commercial areas, where growers followed the IPM programme, a 75\% reduction in insecticide applications was recorded. Previously, over the main growing season, cabbage crops grown in the Pukekohe region each received an average of six insecticide applications (Beck et al. 1992). Also, when crops were left unsprayed or only selective larval insecticides applied, the mortality of pest species due to natural enemies was often high. For example, in mid December, four of five sites had 54-72\% 
of reared larvae parasitised by D. semiclausum (Walker et al. 2002). At the other site, Puni, a high number of insecticide applications were used, particularly on the second summer crop (Fig. 1). This situation was partly due to outbreaks of cabbage aphid (Brevicoryne brassicae). The use of broad-spectrum insecticides for aphid control at this site led to further pest outbreaks of both cabbage aphid and looper larvae probably caused by reduced protection from natural enemies (Walker et al. 2002). Overall there was little disruption to DBM moth populations because of the predominant use of selective insecticides, which are relatively harmless to lepidopteran adults. However, the selective and broad-spectrum insecticides that were applied to control DBM larvae or other caterpillar infestations would have disrupted the links between moth catches and DBM larval populations in crops. Also, mortality from natural enemies may obscure pheromone predictions, particularly infections by $Z$. radicans.

Pheromone trap catches in spring and summer (crops 1 and 2 in our study) did forewarn of DBM larval infestations in three of four commercial crops. However, large moth catches in late summer were not useful indicators of larval infestations. Also, during the high-risk periods for pests, being October through to April, larval infestations would be adequately assessed by normal crop scouting practices because weekly scouting is required to monitor other pest infestations that might require controls. Therefore, pheromone trapping is likely to have only limited value in the present IPM programme for vegetable brassicas. However, during these studies trap catches in early spring (early September) did forewarn of small and potentially damaging larval infestations in late September. Therefore, trap catch data may be useful indicators of emerging DBM larval infestations in early spring, and therefore reduce scouting time in this period, when intensive scouting of crops may not be necessary.

\section{ACKNOWLEDGEMENTS}

We thank the growers for allowing the research to be carried out on their properties. We also thank the Pukekohe Brassica Growers' Group for their application for AGMARDT funding, and AGMARDT and the Fresh Vegetable Industry Research \& Development Grants Committee (Vegfed) for jointly funding this research project. Pranish Prasad gave additional technical assistance.

\section{REFERENCES}

Baker, P.B.; Shelton, A.M.; Andaloro, J.T. 1982: Monitoring of diamondback moth (Lepidoptera: Yponomeutidae) in cabbage with pheromones. J. Econ. Entomol. 75 (6): 1025-1028.

Beck, N.G.; Herman, T.J.B.; Cameron, P.J. 1992: Scouting for lepidopteran pests in commercial cabbage. N.Z. Plant Prot. 45: 31-34.

Berry, N.A. (editor). 2000: Integrated Pest Management for Brassicas. IPM Manual no. 11. Crop \& Food Research, Lincoln.

Suckling, D.M.; Shaw, P.W. 1990: Preliminary trials of mating disruption of light brown apple moth in Nelson. Proc. 43 ${ }^{\text {rd }}$ N.Z. Weed and Pest Control Conf.: 311-316.

Suckling, D.M.; Gibb, A.R.; Daly, J.M.; Rogers, D.J.; Walker, G.P. 2002: Improving the pheromone lure for diamondback moth. N.Z. Plant Prot. 55: 182-187.

Talekar, N.T.; Shelton, A.M. 1993: Biology, ecology and management of the diamondback moth. Ann. Rev. Entomol. 38: 275-301.

Walker, G.P. 2001: IPM for vegetable brassicas. Grower December: 25.

Walker, G.P.; Cameron, P.J.; Berry, N.A. 2001: Implementing an IPM programme for vegetable brassicas in New Zealand. In: The management of diamondback moth and other crucifer pests: Proc. Fourth Int. Workshop. Melbourne, Australia. In press.

Walker, G.P.; Bush, R.; Prasad, P. 2002: Control of diamondback moth in vegetable brassica crops in New Zealand. International Symposium Improving Biocontrol of Plutella xylostella. CIRAD, Montpellier, France. In press. 